\title{
Reduction and characterization of bioaerosols in a wastewater treatment station via ventilation
}

\author{
Xuesong Guo ${ }^{1}$, Pianpian $\mathrm{Wu}^{2}$, Wenjie Ding ${ }^{1}$, Weiyi Zhang ${ }^{3}$, Lin $\mathrm{Li}^{1, *}$ \\ 1. Research Center for Eco-Environmental Sciences, Chinese Academy of Sciences, Beijing 100085, China. E-mail: gxs0122@rcees.ac.cn \\ 2. Regional Water Quality Control Board, Los Angeles, CA 90013, USA \\ 3. Beijing University of Civil Engineering and Architecture, Beijing 100044, China
}

\section{A R T I C L E I N F O}

Article history:

Received 9 October 2013

Revised 12 November 2013

Accepted 13 November 2013

Available online 23 June 2014

Keywords:

Wastewater treatment station

Vertical oxidation ditch

Bioaerosols

Genetic

Clone library

\begin{abstract}
A B S T R A C T
Bioaerosols from wastewater treatment processes are a significant subgroup of atmospheric aerosols. In the present study, airborne microorganisms generated from a wastewater treatment station (WWTS) that uses an oxidation ditch process were diminished by ventilation. Conventional sampling and detection methods combined with cloning/sequencing techniques were applied to determine the groups, concentrations, size distributions, and species diversity of airborne microorganisms before and after ventilation. There were $3021 \pm 537 \mathrm{CFU} / \mathrm{m}^{3}$ of airborne bacteria and $926 \pm 132 \mathrm{CFU} / \mathrm{m}^{3}$ of airborne fungi present in the WWTS bioaerosol. Results showed that the ventilation reduced airborne microorganisms significantly compared to the air in the WWTS. Over $60 \%$ of airborne bacteria and airborne fungi could be reduced after $4 \mathrm{hr}$ of air exchange. The highest removal (92.1\% for airborne bacteria and $89.1 \%$ for fungi) was achieved for 0.65-1.1 $\mu \mathrm{m}$ sized particles. The bioaerosol particles over $4.7 \mu \mathrm{m}$ were also reduced effectively. Large particles tended to be lost by gravitational settling and small particles were generally carried away, which led to the relatively easy reduction of bioaerosol particles $0.65-1.1 \mu \mathrm{m}$ and over $4.7 \mu \mathrm{m}$ in size. An obvious variation occurred in the structure of the bacterial communities when ventilation was applied to control the airborne microorganisms in enclosed spaces.
\end{abstract}

(C) 2014 The Research Center for Eco-Environmental Sciences, Chinese Academy of Sciences. Published by Elsevier B.V.

\section{Introduction}

Bioaerosols present in wastewater treatment plants (WWTP) have gained increasing attention in recent years due to their close correlation with air pollution and possible cause of adverse health effects for plant workers (Fracchia et al., 2006). Many studies have evaluated the biological risks of aerosols by determining the concentrations of viable microorganisms, using different sampling and detection methods (Fannin et al., 1985; Carducci et al., 2000; Bauera et al., 2002; Pascual et al., 2003; Karra and Katsivela, 2007; Stellacci et al., 2010). Previous reports of municipal WWTP bioaerosols have shown that high levels of culturable airborne bacteria and fungi were present in the indoor facilities and the aeration system (Brandi et al., 2000; Sánchez-Monedero et al.,
2008; Li et al., 2011). Raw wastewater contains a large diversity of microorganisms, such as viruses, bacteria, fungi, and protozoans, which may be aerosolized during mechanical agitation and water aeration. Aeration systems are considered the main sources of bioaerosols in WWTP. High numbers of airborne microorganisms have been observed in indoor facilities, possibly explained by internal walls obstructing the dispersal of bioaerosols as well as insufficient ventilation and reduced die-off rates from limited solar radiation.

Many countries are attempting to regulate the impact of bioaerosols and have proposed a number of measures for their control (Hung et al., 2010). Air filtration and UV germicidal irradiation (UVGI) are two air purification systems routinely used for removing or inactivating microorganisms (Riley and Nardell,

\footnotetext{
* Corresponding author. E-mail: leel@rcees.ac.cn (Lin Li).
} 
1989; Green and Scarpino, 2002; Kujundzic et al., 2007). Air filtration systems must be changed periodically and require routine maintenance. Compared with air filtration, UVGI generally provides effective control at a lower cost, with easier installation and maintenance. Both systems, however, initially require adequate ventilation.

Ventilation removes unpleasant smells and excessive moisture, introduces outside air into internal air circulation, prevents air stagnation, and is one of the most important factors in maintaining acceptable indoor air quality. Ventilation dilutes the concentration of microorganisms in the air via air exchange, which is a convenient and economic method of reducing airborne microorganisms. Building ventilation can be divided into mechanical/forced and natural types.

Understanding the microbial characteristics of bioaerosols will help develop effective measures to control their emission. Previous research has investigated the concentrations, particle size distributions, and species diversity of airborne microorganisms at different stages in WWTPs (Fannin et al., 1985; Buttner et al., 2001; Pillai and Ricke, 2002; Grisoli et al., 2009), and their hazards have also been identified (Palmer et al., 1995; Carducci et al., 2000). However, little is known regarding the characteristics, e.g., particle size characteristics and microbial population structure, of airborne bioaerosols removed from the air by ventilation. Bioaerosol monitoring requires appropriate analysis of air samples and detection of microbial wastewater species. In addition to the culture method, molecular biology techniques provide more widely applicable tools in microbial assay (Sawyer et al., 1994; Maron et al., 2005; An et al., 2006).

In the present study, airborne microorganisms generated from a wastewater treatment station (WWTS) that uses the oxidation ditch process were diminished by ventilation. Conventional sampling and detection methods combined with cloning/sequencing techniques were applied to determine the groups, concentrations, size distributions, and species diversity of airborne microorganisms before and after ventilation. The objective was to explore the variation in bioaerosol levels and microbial structures to find a suitable method to reduce airborne microorganisms generated from internal wastewater treatment facilities.

\section{Materials and methods}

\subsection{Station description and sampling locations}

The present study on bioaerosol emissions in a WWTS that uses a vertical oxidation ditch was conducted in September 2012 in Beijing, China. Oxidation ditches have been used in small communities as a cost-effective secondary treatment from the 1960s (Denton, 1997). Compared with the conventional oxidation ditch with intrachannel clarifier, the integrated oxidation ditch with a vertical circle reduces land area by about $50 \%$ and energy consumption by $40 \%$. Its characteristics are compact configuration, simple operation and easy maintenance (Xia and Liu, 2004). This station serves a residential community with a population of 1500 , and has a daily capacity of $100 \mathrm{~m}^{3}$. The oxidation ditch is located indoors for maintaining suitable temperatures in winter. Rotating brushes with a speed of $50 \mathrm{r} / \mathrm{min}$ were installed in the oxidation ditch to aerate the water. The average chemical oxygen demand (COD) and $\mathrm{NH}_{4}^{+}-\mathrm{N}$ in the influent sewage were 356 and $43.8 \mathrm{mg} / \mathrm{L}$, respectively. The removal efficiencies were 91.1\% for COD and $98.2 \%$ for $\mathrm{NH}_{4}^{+}-\mathrm{N}$ after $10 \mathrm{hr}$ of hydraulic retention.

Sampling sites were established at the center of the WWTS (SEP), a clean room of the office building (IDC) and outside upwind (ODC) in the present study (Fig. 1 and Table 1). Microbial samples for microbiological assays were collected between 10:00 am and 11:30 am within one day. During sampling, temperature, relative humidity $(\mathrm{RH})$, and wind speed were also measured (Table 1). A Dewpoint Thermohygrometer (WD-35612, OAKTON, Germany) was used to determine RH and temperature. The wind speed was recorded by a portable anemometer (HD2303, Delta OHM, Italy). A ventilator (FA-50, Shanghai, China) was used for air exchange and its flow rate was $50 \mathrm{~m}^{3} / \mathrm{min}$.

\subsection{Airborne microorganism capture}

A Six-stage Viable Andersen Cascade Impactor (228-9530 K, SKC Gulf Coast Inc., USA), which is a bioaerosol and microbial particle sizing sampler designed to measure the concentration and particle size distribution of aerobic bacteria and fungi in intramural or ambient air, was used to capture airborne microorganisms on-site. The sampler is constructed from aluminum and consists of a series of six consecutive stages. Each stage contains a plate perforated by 400 holes, which are of constant size for a given stage, but decrease for each succeeding stage. Airborne particles are separated into six fractions, and the aerodynamic cut-size diameters in the six stages are: $>7.0 \mu \mathrm{m}$ (stage 1), 4.7-7.0 $\mu \mathrm{m}$ (stage 2), 3.3-4.7 $\mu \mathrm{m}$ (stage 3), 2.1-3.3 $\mu \mathrm{m}$ (stage 4), 1.1-2.1 $\mu \mathrm{m}$ (stage 5), and 0.65$1.1 \mu \mathrm{m}$ (stage 6), respectively. Directly below each stage is a glass Petri dish containing a suitable medium. The stages are held together by three spring clamps, and are gasketed with O-ring seals. Air is drawn through the sampler by means of a pump, at a rate of $28.3 \mathrm{~L} / \mathrm{min}$.

All inside surfaces were sterile until sampling. Sampling time was typically 2-3 min and impaction volume was 56.6$84.9 \mathrm{~L}$. Once the required volume of air had been drawn through, the dishes were removed from the sampler, covered, inverted, and incubated. Three replicates were taken consecutively at every sampling site. After each sample was collected, the sampler was sterilized with $75 \%$ ethanol solution. Airborne bacteria were incubated in Nutrient agar (BR, Aoboxing Biotech,

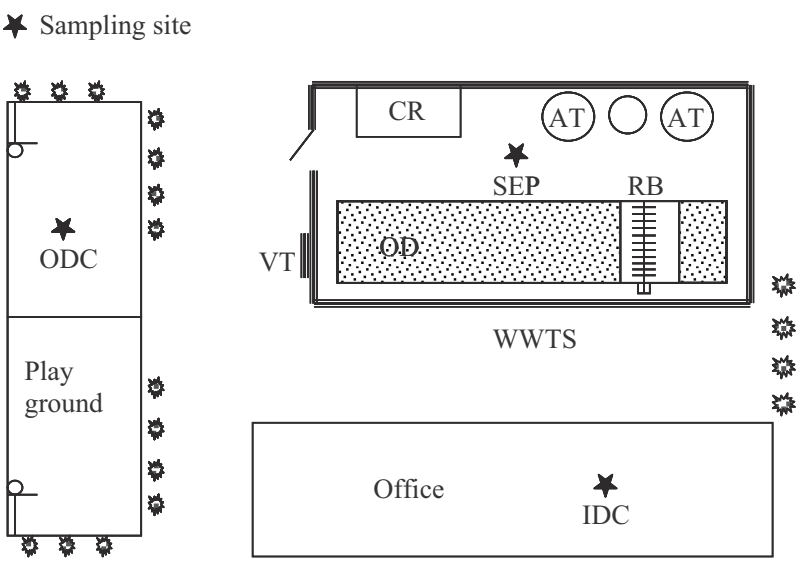

Fig. 1 - Schematic diagram of sampling site locations in the wastewater treatment station. WWTS: wastewater treatment station; OD: oxidation ditch; RB: rotating brushes; CR: control room; VT: ventilator; ODC: outdoor control; IDC: indoor control; AT: advanced treatment. 
Table 1 - Sampling locations and meteorological conditions.

\begin{tabular}{lcccc} 
Samples points & Description & $\mathrm{T}\left({ }^{\circ} \mathrm{C}\right)$ & $\mathrm{RH}(\%)$ & WS $(\mathrm{m} / \mathrm{sec})$ \\
\hline SEP & BV & 23 & 53 & ND \\
SEPV & AV & 23 & 51 & ND \\
IDC & BV & 24 & 42 & ND \\
ODC & - & 23 & 48 & 0.17
\end{tabular}

AV: after ventilation; BV: before ventilation; IDC: indoor control; ODC: outdoor control; ND: not detected; RH: relative humidity;

$\mathrm{T}$ : temperature; WS: wind speed; All samples were sampled at $1.5 \mathrm{~m}$ above ground level.

Co., Beijing, China) at $30^{\circ} \mathrm{C}$ for $48 \mathrm{hr}$, and fungi were cultivated in Rose Bengal Medium (BR, Aoboxing Biotech Co., China) at $30^{\circ} \mathrm{C}$ for 7 days. Positive-hole correction was used to determine colony count concentrations (Andersen 1958; Macher 1989; Evans et al., 2000). Results were calculated as the geometric mean of the replicates, expressed as colony-forming units per cubic meter of air $\left(\mathrm{CFU} / \mathrm{m}^{3}\right)$. The control measurements were performed in a clean room located in the office building (IDC) and outside of the WWTS (ODC).

\subsection{Microbiological analysis}

In the present study, fungal cultures were identified using routine morphological tests (Dai 1987; Li and Liu, 2009). The microbial populations of airborne bacteria were assayed with molecular tools. Before analysis, the bacterial colonies incubated in nutrient agar were suspended in $400 \mu \mathrm{L}$ of buffer (Orsini et al., 2002).

\subsubsection{DNA extraction and PCR amplification}

The DNA extraction and PCR amplification methods used have been described previously (Han et al., 2012). Total DNA isolation was accomplished with a DNA Autoplate (TanBead, Taiwan) using the Automatic Platform for Magnetic System-16 (TanBead, Taiwan). Universal primers F16S-27 (5'-AGAGTTTGATCCTGG CTCAG-3') and R16S-1492 (5'-CGGTTACCTTGTTACGACTTC-3') were used to amplify eubacterial $16 \mathrm{~S}$ rDNA segments. The PCR amplification reaction was performed using the Gene AmpR PCR System (9700, AB, USA) at a final volume of $50 \mu \mathrm{L}$. Clones were cultured on LB medium with X-gal, IPTG and Amp. A total of 60 clones were selected for PCR detection, and their positive clones were submitted for sequencing using the ABI 3730DXL DNA sequencer ( $A B, U S A)$.

1.3.2. Clone library construction and phylogenetic analysis of sequences

All sequences obtained from the clone libraries were manually checked and trimmed to exclude vector sequences, then checked for chimeras using Bellerophon on the GreenGenes website (http://greengenes.lbl.gov/). These sequences were aligned using the DNAMAN software (Lynnon Biosoft, Canada). Aligned sequences were grouped into universal operational taxonomic units (OTUs) at a threshold of $97 \%$ minimum similarity; individual sequences were also grouped into OTUs to identify bacterial distribution in bioaerosols from different sampling sites. They were named as "sampling port namenumber" in the present study. The representative sequence of each OTU in the group-specific libraries was aligned to the NCBI database by the BLAST website. To identify the phylogenetic affiliation of all OTUs, a phylogenetic tree including representative sequences of each OTU and related sequences from the previous NCBI database was constructed using the neighbor joining algorithm of MEGA version 3.1, USA. The partial sequences of the 16S rRNA genes obtained in this study were submitted to the NCBI database under accession numbers shown in Table 2.

\subsubsection{Diversity and richness estimation of clone libraries}

To determine whether the size of a clone library was large enough to represent the diversity of an original community, the equation $C=1-(n / N)$ was applied to calculate the coverage of each clone library, in which $n$ is the number of unique clones and $\mathrm{N}$ is the total number of sequences examined (Good 1953). The microbial diversity of each clone library was estimated by the Shannon Wiener index $(H)$ (Ding et al., 2008).

\section{Results and discussion}

\subsection{Characteristics of airborne microorganisms in the WWTS}

Rotating aeration brushes were installed in the oxidation ditch to provide wastewater aeration and linear liquid motion. The speed of the rotating brushes was maintained at $50 \mathrm{r} / \mathrm{min}$. The transfer of microorganisms from water to air occurs mainly during aeration. Microbial samples were collected from the sampling port SEP (Fig. 1) to investigate the concentration of airborne microorganisms in the treatment station. As shown in Fig. 2, there were $3021 \pm 537 \mathrm{CFU} / \mathrm{m}^{3}$ of airborne bacteria and $926 \pm 132 \mathrm{CFU} / \mathrm{m}^{3}$ of airborne fungi present in the WWTS, which showed that the concentration of bacteria was much higher than that of fungi. The percentage of fungi in total microorganisms was $23.5 \%$. About $62.4 \%$ of bacteria and $74.3 \%$ of fungi were attached to particles sized within the range of $1.1-4.7 \mu \mathrm{m}$.

The mean concentrations of heterotrophic bacteria and fungi in the indoor control (IDC, sampled from a clean room in the WWTS, Fig. 1) were 57 and $193 \mathrm{CFU} / \mathrm{m}^{3}$, respectively,

Table 2 - Accession numbers of OTUs from all samples in GenBank database.

\begin{tabular}{lll}
$\begin{array}{c}\text { Sampling } \\
\text { site }\end{array}$ & $\begin{array}{l}\text { Names of OTU in } \\
\text { Figs. } 6 \text { and } 7\end{array}$ & \multicolumn{1}{c}{ Accession numbers } \\
\hline SEP & SEP-1 to SEP-7 & KF228905-KF228911 \\
SEPV & SEPV-1 to SEPV-4 & KF228912-KF228915 \\
& SEPV-6 to SEPV-8 & KF228916-KF228918 \\
& SEPV-10 & KF228919 \\
ODC & ODC-1 to ODC-5 & KF453792-KF453796 \\
& ODC-8 & KF453797 \\
& ODC-16 & KF453798 \\
& ODC-18 to ODC-19 & KF453799-KF453800 KF453801 \\
& ODC-40 & KF453802 \\
& ODC-47 & \\
\end{tabular}

SEP: samples collected at SEP shown in Fig. 1; SEPV: samples collected at SEP after ventilation; ODC: outdoor control. 


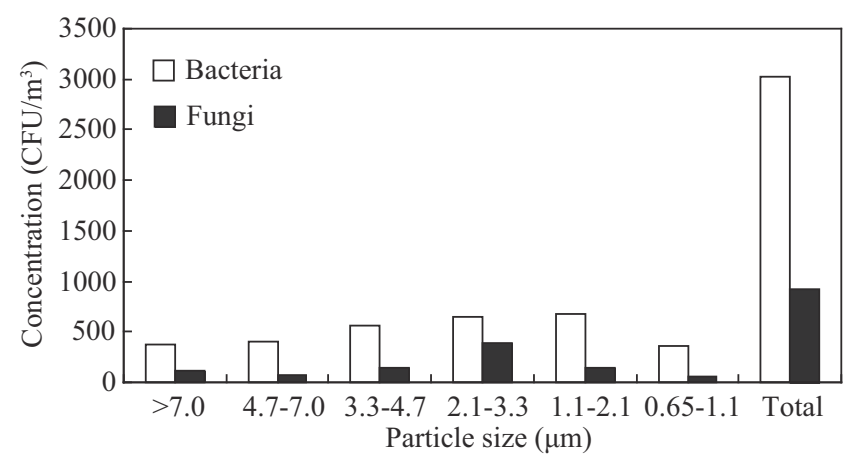

Fig. 2 - Airborne bacteria and fungi emission in wastewater treatment station.

approximately 52 times lower (for bacteria) and 5 times lower (for fungi) than that in samples collected at SEP. High numbers of airborne microorganisms were present in the WWTS, possibly explained by the walls and roof of the WWTS obstructing the dispersal of bioaerosols and preventing damage to microorganisms from solar radiation. Insufficient ventilation and reduced die-off rates led to the accumulation of microorganisms in the station atmosphere.

The concentrations of culturable bacteria present in the WWTS exceeded the National Indoor Air Quality Standard of China $\left(2500 \mathrm{CFU} / \mathrm{m}^{3}\right)$ (GB/T 18883-2002, 2002).

\subsection{Reduction of airborne microorganisms by ventilation}

\subsubsection{Level of airborne bacteria and fungi after ventilation} Ventilation was applied in the present study to reduce the level of airborne microorganisms in the station. Fig. 3 shows the removal efficiencies of airborne bacteria and fungi at different air change times. Both airborne bacteria and fungi were decreased obviously with increasing air change time. After $2 \mathrm{hr}$ of ventilation, the level of bacteria in the WWTS air reached the National Indoor Air Quality Standard of China. The removal efficiencies increased gradually and became steady after $4 \mathrm{hr}$ of ventilation. As shown in Fig. 3, $66.33 \%$ of airborne bacteria and $62.95 \%$ of fungi were reduced within

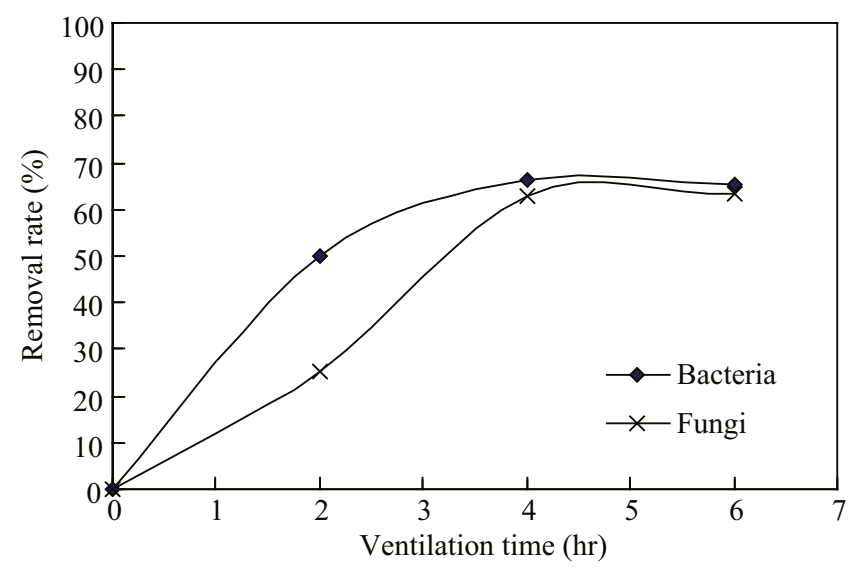

Fig. 3 - The removal efficiencies of airborne bacteria and fungi.
$4 \mathrm{hr}$ of air exchange. Airborne bacteria and fungi had similar removal efficiencies.

Ventilation changes or replaces air in a space to provide high indoor air quality (i.e., it controls temperature, replenishes oxygen, and removes moisture, odors, smoke, heat, dust, airborne bacteria, and carbon dioxide). Buildings are ventilated to introduce outdoor air inside and distribute it for the purpose of maintaining occupant health. Fresh air was introduced from outside of the station. Only $660 \pm 113 \mathrm{CFU} / \mathrm{m}^{3}$ of culturable bacteria and $94 \pm 37 \mathrm{CFU} / \mathrm{m}^{3}$ of culturable fungi were detected at the ODC sampling site. Dilution by fresh air from outside was a significant factor in decreasing levels of bioaerosols after ventilation. The amount of bacteria and fungi in the air began to increase when the ventilation time was as high as $6 \mathrm{hr}$ (Fig. 4). High frequency of ventilation and air exchange will accelerate air movement, resulting in the increasing generation of airborne microorganisms. The basic elements for building ventilation are the outdoor air ventilation rate, ventilation time, the airflow direction, and the air distribution or airflow pattern in the space. As the ventilation rate, airflow direction and the air distribution had been set in advance, the air exchange time is the most important parameter in the present study. Therefore, $4 \mathrm{hr}$ was selected as the ventilation time.

2.2.2. Reduction of airborne bacteria and fungi for individual particle sizes

An Andersen sampler can separate airborne particles by collecting them in stages using different hole sizes, which provides information on cell density and particle size (Andersen 1958; Brandi et al., 2000). The percentages of particles in individual size ranges changed obviously after ventilation. Figs. 4 and 5 demonstrate the particle size distributions and the removal efficiencies of airborne bacteria and fungi for each particle size. Both airborne bacteria and fungi detected on 0.65-1.1 $\mu \mathrm{m}$ sized particles achieved the highest removal under the air change time of $4 \mathrm{hr}$, with removal efficiencies of $92.1 \%$ and $89.1 \%$, respectively. Significant removal also occurred for bioaerosol particles larger than $4.7 \mu \mathrm{m}$. Conversely, airborne bacteria detected on particles ranging from 1.1 to $3.3 \mu \mathrm{m}$ and fungi on 3.3 to $4.7 \mu \mathrm{m}$ sized particles were difficult to remove.

Removal efficiency was not only influenced by the amount of airborne microorganisms, but also by their particle sizes. Large particles tended to fall rather quickly due to gravitational settling, whereas smaller particles were more likely to be carried away. Therefore, airborne bacteria and fungi on particles ranging from 0.65 to $1.1 \mu \mathrm{m}$ and over $4.7 \mu \mathrm{m}$ in size were reduced more easily via ventilation.

The risks associated with exposure to aerosols are not only related to species and concentration but also to the size of aerosolized particles (Reponen et al., 1992; Brandi et al., 2000). Smaller particles (especially $<5 \mu \mathrm{m}$ ) can penetrate the lower airways of humans and lead to allergies or asthma. The timing of ventilation was suitable for reducing small bioaerosols that carry greater harm to on-site workers.

\subsection{Microbial structure}

\subsubsection{Clone library coverage}

The diversity and coverage of the 16S rDNA-based phylotypes were determined by analysis of clones from each of the clone 

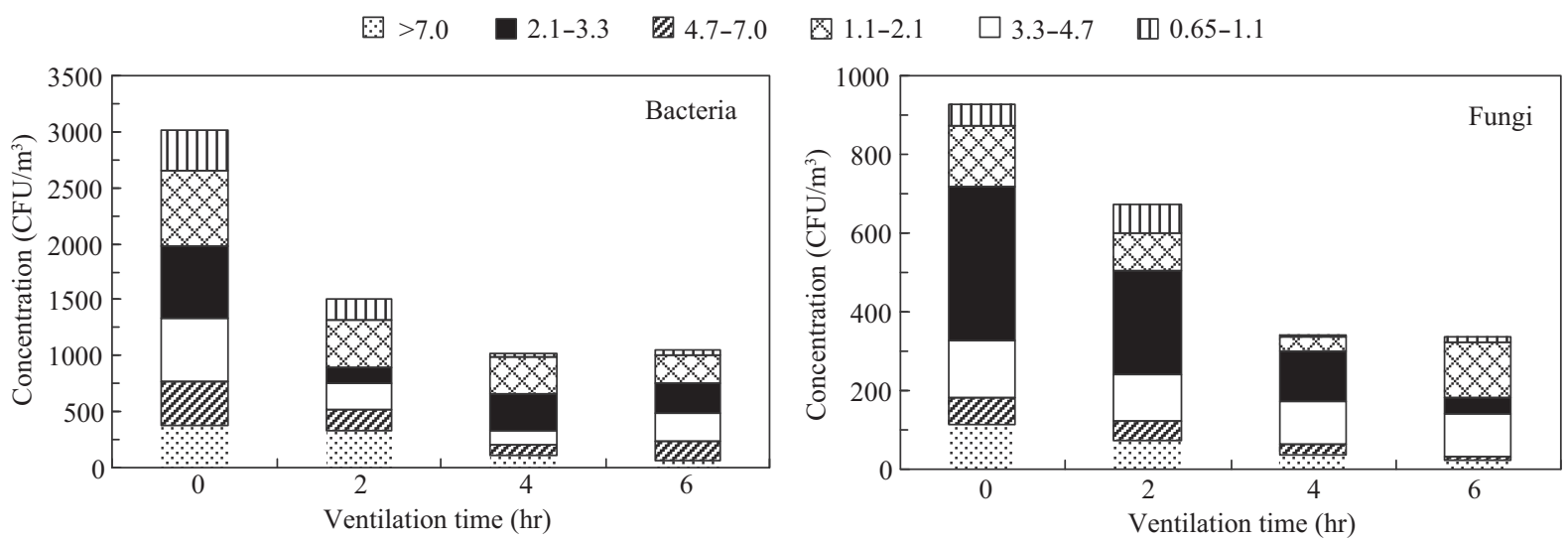

Fig. 4 - Particle size distributions of airborne bacteria and fungi.

libraries. A total of 149 clones were compared. There were 7 different OTUs among the 50 screened clones from the SEP (sample collected before ventilation) clone library, whereas 8 OTUs from 49 screened clones and 11 OTUs from 50 screened clones were identified from the SEPV (sample collected after $4 \mathrm{hr}$ of ventilation) and ODC clone libraries, respectively. Coverage analysis indicated that the bioaerosol libraries represented approximately $94.0 \%$ of the total number of clones examined, providing a dependable inventory of the bacterial 16S rRNA gene sequences present in the bioaerosols.

\subsubsection{Genetic structure of airborne bacterial communities}

Sequences were assigned to a bacterial phylum according to their position in the phylogenetic tree (Figs. 6 and 7). The bacteria that most closely represented the OTUs' microorganisms were those isolated from activated sludge in the wastewater treatment plant and soil ecosystems.

The majority of sequences in SEP were assigned to Lysinibacillus sphaericus (54.0\%) and Bacillus sp. (42.0\%) with Bacillus pichinotyi, B. cereus, B. firmus and B. thuringiensis serovar. The minor groups were the Paucisalibacillus globules (Fig. 8). They all belonged to Firmicutes. Similar results were obtained in previous reports (Li et al., 2013). For SEPV, the most represented bacterial groups were Bacillus sp. (32.7\%) and Lysinibacillus sp. (46.9\%) with L. sphaericus, and L. fusiformis. The other OTUs were related to Breuundimonas sp., Brevibacillus invocatus and Achromobacter xylosoxidans. A multiplicity of microorganisms appeared in the atmosphere outside. Over $38.0 \%$ of the bacterial groups in the ODC clone library were uncultured bacteria. Other identified groups were Bacillus sp. (20.0\%) and Breuundimonas sp. (14.0\%). Brevibacillus, Arthrobacter, Psychrobacter and Pannonibacter were minor groups. These sequence results suggest that Lysinibacillus OTUs were widespread within SEP and SEPV, and that the Bacillus OTUs were clustered in all sampling sites. L. sphaericus is a Gram-positive, mesophilic, rod-shaped bacterium. Under harsh conditions, they can form dormant endospores that are resistant to heat, chemicals, and ultraviolet light. These spores may remain viable for a long time. Under stressful environmental conditions, the cells of Bacillus produce oval endospores that remain dormant for extended periods and can invade respiratory epithelial cells and cause pulmonary infection. Due to their biodegradation of organic compounds and hazardous substances, Bacillus is widespread in water (Shokrollahzadeh et al., 2008; Zulkifly et al., 2010) and a significant contributor to bioaerosols in WWTS atmospheres.
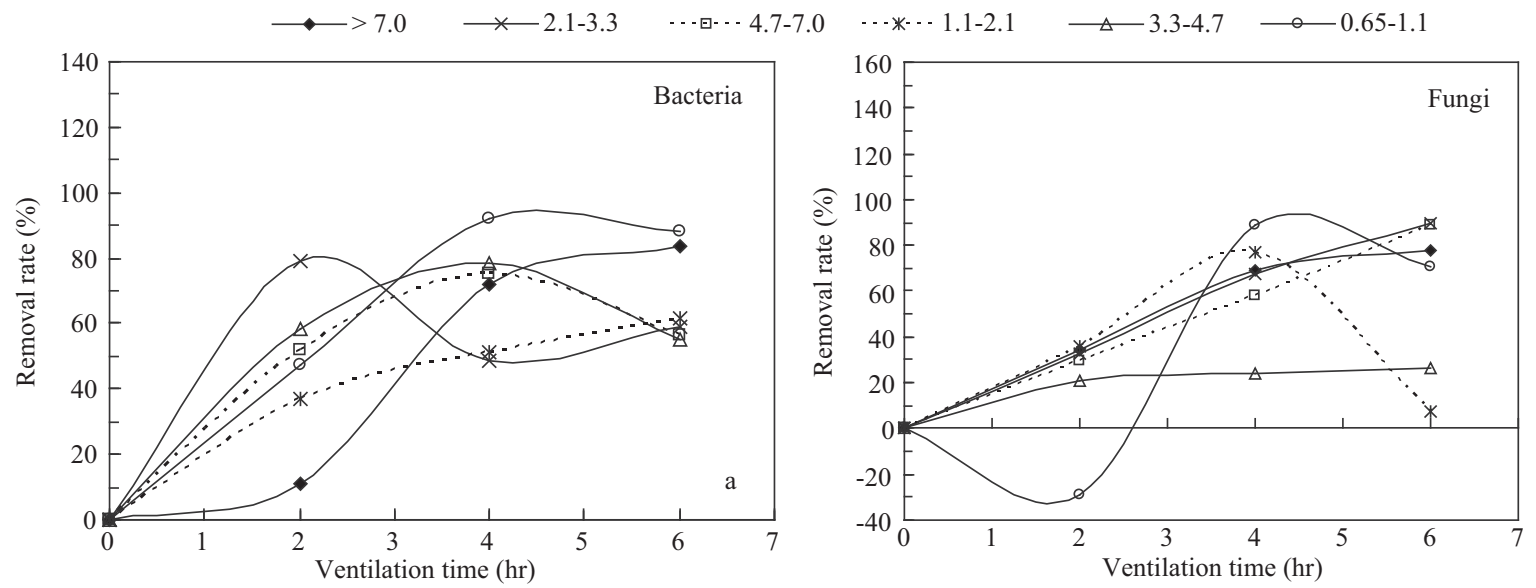

Fig. 5 - Removal efficiencies of airborne bacteria and fungi in each particle size. 


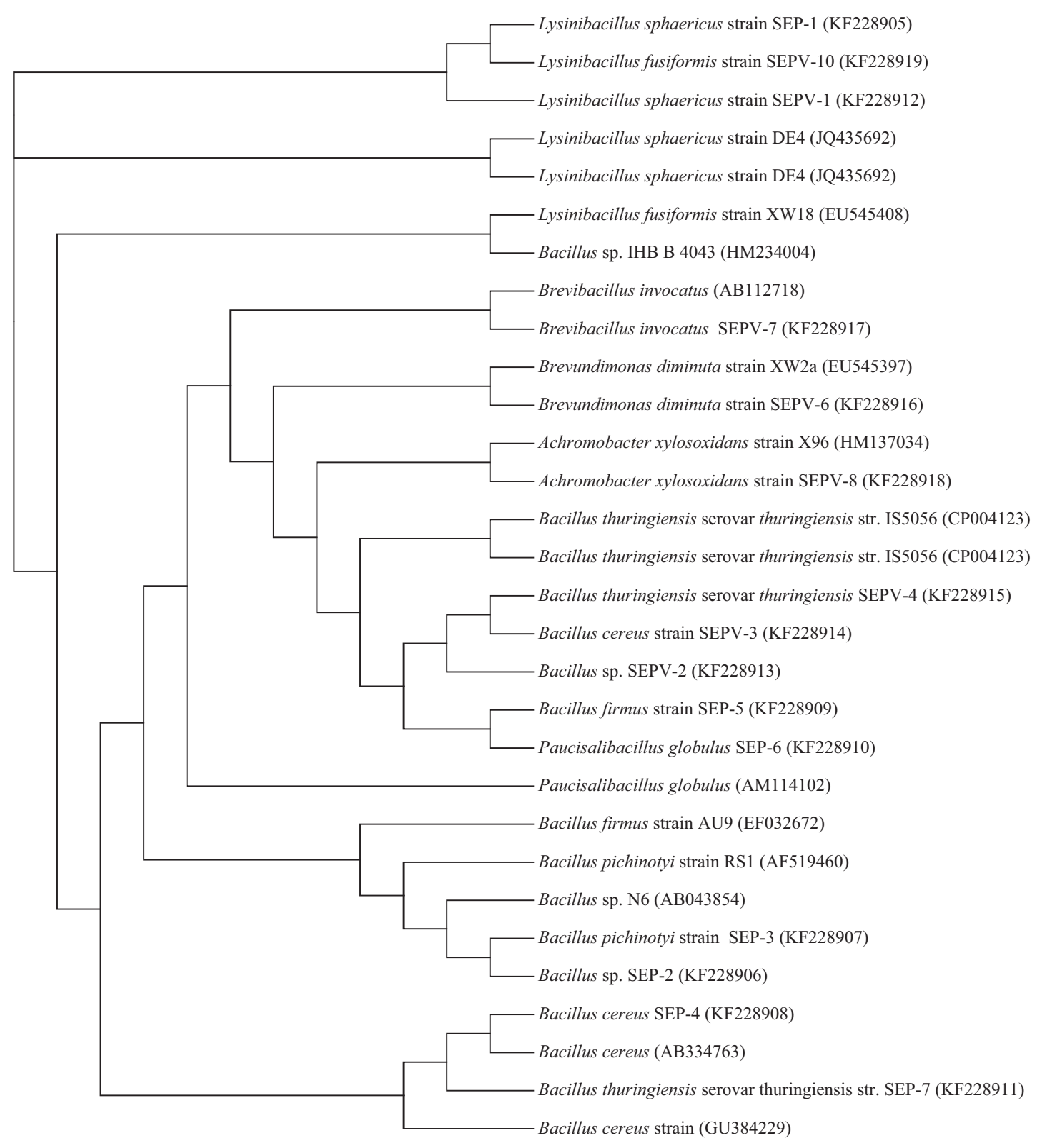

Fig. 6 - Phylogenetic tree showing the relationship of representative sequences of OTUs in SEP and SEPV and reference sequences in GenBank. SEPV: Samples collected at SEP shown in Fig. 1 after ventilation; ODC: Outdoor control.

The diversities of bacterial species were 1.24 for SEP, 1.70 for SEPV and 2.19 for ODC. The ODC site presented the highest species richness among the three clone libraries. The diversity of bacteria collected after ventilation (SEPV) increased notably compared to that sampled before air exchange (SEP) and was less than the level of ODC.

\subsubsection{Variation of OTU before and after ventilation}

The distribution and diversity of bacteria in the bioaerosols varied considerably before and after ventilation. A similar phenomenon occurred in the proportions of Lysinibacillus sp. and Bacillus sp., the major phyla of identified bacteria, in SEP and SEPV. Obvious decreases were observed in Lysinibacillus percentages, from $54.0 \%$ in SEP to $46.9 \%$ in SEPV, and Bacillus sp. percentages, from $42.0 \%$ in SEP to $32.6 \%$ in SEPV (Fig. 8). Five OTUs (21 clones in total, KF228906, KF228909 and KF228911) formed Bacillus sp. in SEP. They were close to cloned 16S rDNA isolated from aquatic and soil environments. Two OTUs (KF228906 and KF228909) belonging to B. pichinotyi and B. firmus disappeared after air exchange, indicating that these two species of bacteria were likely removed. Four OTUs representing two species of Breuundimonas sp. and Brevibacillus sp. were present in SEPV, but were not found in SEP. The phylogenetic affiliation of the OTUs revealed that there were two groups of OTUs, Brevundimonas sp. and Brevibacillus sp., originally found in outside air (ODC) and also in SEPV. Compared with that collected from SEP, the distribution and proportion of Breuundimonas sp. and Brevibacillus sp. increased 


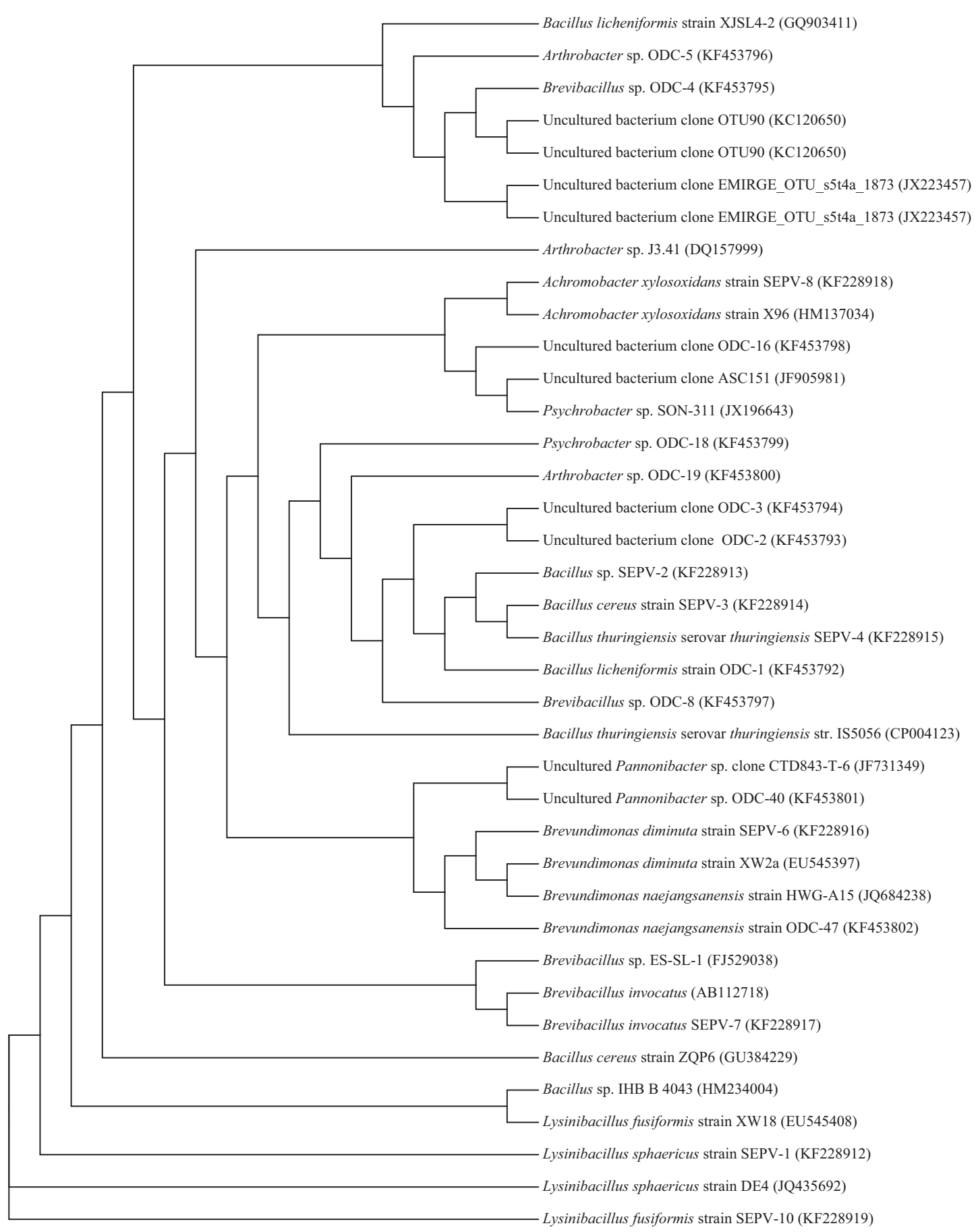

Fig. 7 - Phylogenetic tree showing the relationship of representative sequences of OTUs in SEPV and ODC and reference sequences in GenBank.

after air exchange (SEPV), indicating they might be brought by ventilation from outside of the WWTS. This led to the increase in SEPV diversity, which was in agreement with the Shannon Index results. All bacteria in SEP identified by DNA sequence analysis belonged to Firmicutes. Proteobacteria emerged in the atmosphere of the WWTS after ventilation. The air exchange caused the variation in diversity and microbial structure of the airborne bacteria in the WWTS by carrying in outside bioaerosols.
Most wastewater treatment processes are conducted by automatic systems without human labor. However, some WWTP workers still remain on-site for facility maintenance. It is necessary to explore effective methods to control bioaerosols. As UVGI can inactivate microorganisms, adequate ventilation combined with ultraviolet sterilization is probably an effective measure to protect on-site workers. In addition, installation of air filtering devices at the air intake also prevents contamination by outside microorganisms. 


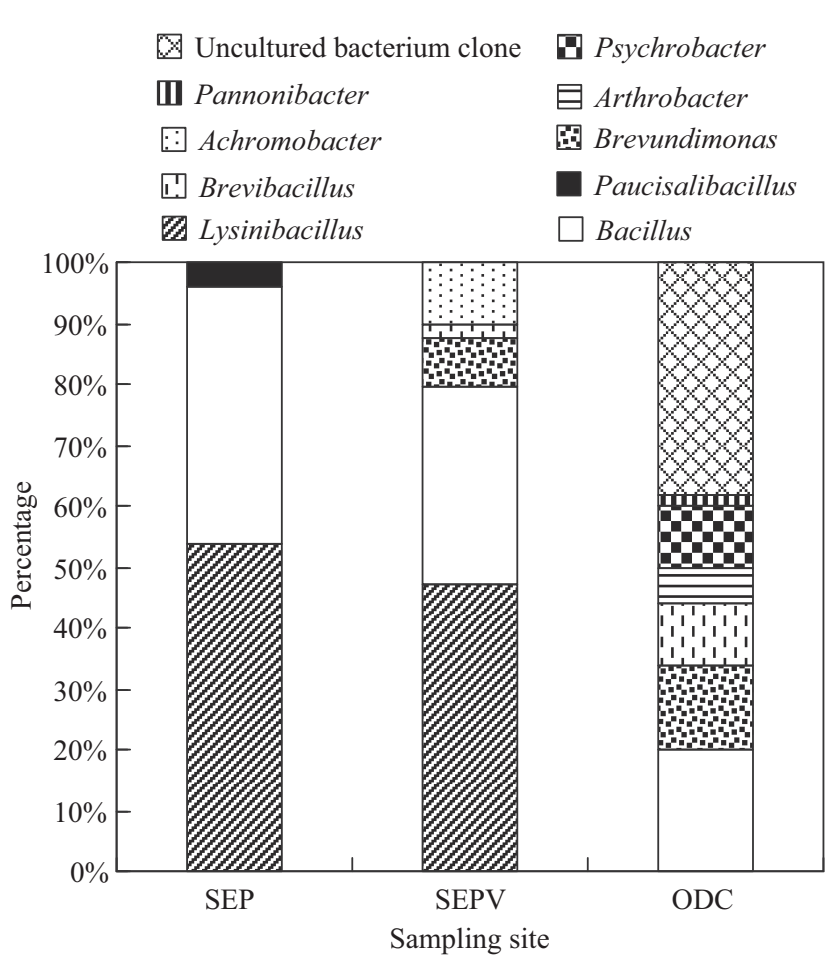

Fig. 8 - Relative phylotype frequencies of clones isolated from examined samples.

\section{Conclusions}

The airborne bacteria and fungi detected in the WWTS were $3021 \pm 537$ and $926 \pm 132 \mathrm{CFU} / \mathrm{m}^{3}$, respectively. Most bacteria and fungi were detected on particles $1.1-4.7 \mu \mathrm{m}$ in size. Airborne bacteria and fungi had similar removal efficiencies via ventilation, with $66.33 \%$ of airborne bacteria and $62.95 \%$ of fungi reduced at the air change time of $4 \mathrm{hr}$. After $2 \mathrm{hr}$ of ventilation, the level of bacteria in air reached the National Indoor Air Quality Standard of China. Airborne microorganisms with particle sizes within $0.65-1.1 \mu \mathrm{m}$ and over $4.7 \mu \mathrm{m}$ were reduced more easily via ventilation. The decreases in airborne microorganisms were likely associated with removal of small particles by outdoor air and gravitational settling of the large particles $(>4.7 \mu \mathrm{m})$.

The diversities and structures of the bacterial communities increased after adequate ventilation. Dominant groups characterized by DNA sequence analysis were found to belong to Bacillus sp. and Lysinibacillus sp. Airborne microorganism concentrations were reduced effectively, while obvious variations occurred in the structure of the bacterial communities when air exchange was applied to control the airborne microorganisms in indoor wastewater treatment facilities. Some species present in the outdoor air might be transported into the station via air exchange, resulting in increased species diversity and varied microbial structure.

As bioaerosols contain viruses as well as different bacteria and fungi, they may cause potential health hazards to plant workers and adjacent communities. Industrial hygienists are becoming increasingly concerned about the potential hazards presented by viable biological aerosols in the workplace. From a human health point of view, it is necessary to develop a multidisciplinary research related to the association between ventilation and health.

\section{Acknowledgments}

We thank Dr. Watts for the English revision of the manuscript. The work was financially supported by the National Key Technology R \& D Program of China (No. 2012BAC13B04-08) and the National Natural Science Foundation of China (Nos. 51178451 and 51221892).

\section{R E F E R E N C E S}

An, H.R., Mainelis, G., White, L., 2006. Development and calibration of real-time PCR for quantification of airborne microorganisms in air samples. Atmos. Environ. 40 (40), 7924-7939.

Andersen, A.A., 1958. New sampler for the collection, sizing, and enumeration of viable airborne particles. J. Bacteriol. 76 (5), 471-484.

Bauera, H., Fuerhackerb, M., Zibuschkab, F., Schmida, H., Puxbaum, H., 2002. Bacteria and fungi in aerosols generated by two different types of wastewater treatment plants. Water Res. 36 (16), 3965-3970.

Brandi, G., Sisti, M., Amagliani, G., 2000. Evaluation of the environmental impact of microbial aerosols generated by wastewater treatment plants utilizing different aeration systems. J. Appl. Microbiol. 88 (5), 845-852.

Buttner, M.P., Cruz-Perez, P., Stetzenbach, L.D., 2001. Enhanced detection of surface-associated bacteria in indoor environments by quantitative PCR. Appl. Environ. Microbiol. 67 (6), 2564-2570.

Carducci, A., Tozzi, E., Rubulotta, E., Casini, B., Cantiani, L., Rovini, E., 2000. Assessing airborne biological hazard from urban wastewater treatment. Water Res. 34 (4), 1173-1178.

Dai, F.L., 1987. Morphology and Taxonomy of Fungi. Science Press, Beijing, China, pp. 176-182.

Ding, Y., Wu, W.X., Han, Z.Y., Chen, Y.X., 2008. Correlation of reactor performance and bacterial community composition during the removal of trimethylamine in three-stage biofilters. Biochem. Eng. J. 38 (2), 248-258.

Evans, G.F., Highsmith, R.V., Sheldon, L.S., Suggs, J.C., Williams, R. W., Zweidinger, R.B., et al., 2000. The 1999 Fresno Particulate Matter Exposure Studies: comparison of community, outdoor, and residential PM mass measurements. J. Air Waste Manag. Assoc. 50 (11), 1887-1896.

Fannin, K.F., Vana, S.C., Jakubowski, W., 1985. Effect of an activated-sludge waste-water treatment-plant on ambient air densities of aerosols containing bacteria and viruses. Appl. Environ. Microbiol. 49 (5), 1191-1196.

Fracchia, L., Pietronave, S., Rinaldi, M., Martinotti, M.G., 2006. Site-related airborne biological hazard and seasonal variations in two wastewater treatment plants. Water Res. 40 (10), 1985-1994.

GB/T 18883-2002, 2002. Standards for Indoor Air Quality. Standards Press of China, Beijing, PR China.

Good, I.J., 1953. The population frequencies of species and the estimation of population parameters. Biometrika 40 (3-4), 237-264.

Green, F.C., Scarpino, P.V., 2002. The use of ultraviolet germicidal irradiation (UVGI) in disinfection of airborne bacteria. Environ. Eng. Policy 3 (1), 101-107.

Grisoli, P., Rodolfi, M., Villani, S., Grignani, E., Cottica, D., Berri, A., et al., 2009. Assessment of airborne microorganism 
contamination in an industrial area characterized by an open composting facility and a wastewater treatment plant. Environ. Res. 109 (2), 135-142.

Han, Y.P., Li, L., Liu, J.X., Zhang, M.Z., 2012. Microbial structure and chemical components of aerosols caused by rotating brushes in a wastewater treatment plant. Environ. Sci. Pollut. Res. 19 (9), 4097-4108.

Hung, H.F., Kuo, Y.M., Chien, C.C., Chen, C.C., 2010. Use of floating balls for reducing bacterial aerosol emissions from aeration in wastewater treatment processes. J. Hazard. Mater. 175 (1-3), 866-871.

Karra, S., Katsivela, E., 2007. Microorganisms in bioaerosols emissions from wastewater treatment plants during summer at a Mediterranean site. Water Res. 41 (6), 1355-1365.

Kujundzic, E., Hernandez, M., Miller, S.L., 2007. Ultraviolet germicidal irradiation inactivation of airborne fungal spores and bacteria in upper-room air and HVAC in-duct configurations. J. Environ. Eng. Sci. 6 (1), 1-9.

Li, L., Liu, J.X., 2009. Identification and characteristic analysis of microorganisms from the integrated bioreactor in treatment of odors. Inter. J. Environ. Pollut. 37 (2-3), 216-234.

Li, L., Gao, M., Liu, J.X., 2011. Distribution characterization of microbial aerosols emitted from a wastewater treatment plant using the Orbal oxidation ditch process. Process Biochem. 46 (4), 910-915

Li, L., Han, Y.P., Liu, J.X., 2013. Assessing genetic structure, diversity of bacterial aerosol from aeration system in an oxidation ditch wastewater treatment plant by culture methods and bio-molecular tools. Environ. Monit. Asses. 185 (1), 603-613.

Macher, J.M., 1989. Positive-hole correction of multiple-jet impactors for collecting viable microorganisms. Am. Ind. Hyg. Assoc. J. 50 (11), 561-568.

Maron, P.A., Lejon, D.P.H., Carvalho, E., Bizet, K., Lemanceau, P., Ranjard, L., 2005. Assessing genetic structure and diversity of airborne bacterial communities by DNA fingerprinting and 16S rDNA clone library. Atmos. Environ. 39 (20), 3687-3695.

Orsini, M., Laurenti, P., Boninti, F., Arzani, D., Ianni, A., Romano-Spica, V., 2002. A molecular typing approach for evaluating bioaerosol exposure in wastewater treatment plant workers. Water Res. 36 (5), 1375-1378.
Palmer, C.J., Bonilla, G.F., Roll, B., Paszko-Kolva, C., Sangermano, L. R., Fujioka, R.H., 1995. Detection of Legionella species in reclaimed water and air with the environAmp Legionella PCR kit and direct fluorescent antibody staining. Appl. Environ. Microbiol. 61, 407-412.

Pascual, L., Pérez-Luz, S., Yáñez, M.A., Santamaría, A., Gibert, K., Salgot, M., et al., 2003. Bioaerosol emission from wastewater treatment plants. Aerobiologia 19, 261-270.

Pillai, S.D., Ricke, S.C., 2002. Bioaerosols from municipal and animal wastes: background and contemporary issues. Can. J. Microbiol. 48 (8), 681-696.

Reponen, T., Lehtonen, M., Raunemaa, T., Nevalainen, A., 1992. Effect of indoor sources on fungal spore concentrations and size distributions. J. Aerosol Sci. 23 (S1), 663-666.

Riley, R.L., Nardell, E.A., 1989. Clearing the air. The theory and application of ultraviolet air disinfection. Amer. Rev. Res. Dis. 139 (5), 1286-1294.

Sánchez-Monedero, M.A., Aguilar, M.I., Fenoll, R., Roig, A., 2008. Effect of the aeration system on the levels of airborne microorganisms generated at wastewater treatment plants. Water Res. 42 (14), 3739-3744.

Sawyer, M.H., Chamberlin, C.J., Wu, Y.N., Aintablian, N., Wallace, M.R., 1994. Detection of varicella-zoster virus DNA in air samples from hospital rooms. J. Infect. Dis. 169 (1), 91-94.

Shokrollahzadeh, S., Azizmohseni, F., Golmohammad, F., Shokouhi, H., Khademhaghighat, F., 2008. Biodegradation potential and bacterial diversity of a petrochemical wastewater treatment plant in Iran. Bioresour. Technol. 99 (14), 6127-6133.

Stellacci, P., Liberti, L., Notarnicola, M., Haas, C.N., 2010. Hygienic sustainability of site location of wastewater treatment plants: a case study. II. Estimating airborne biological hazard. Desalination 253 (1-3), 106-111.

Xia, S.B., Liu, J.X., 2004. An innovative integrated oxidation ditch with vertical circle (IODVC) for wastewater treatment. J. Environ. Sci. 16 (3), 367-370.

Zulkifly, A.H., Roslan, D.D., Hamid, A.A.A., Hamdan, S., Huyop, F., 2010. Biodegradation of low concentration of monochloroacetic acid-degrading Bacillus sp. TW1 isolated from terengganu water treatment and distribution plant. J. Appl. Sci. 10 (22), 2940-2944. 